\title{
The Role of Hesperetin in the Management of Diabetes Mellitus and Its Complications
}

\author{
J. Revathy ${ }^{1, *}$, S. Sheik Abdullah ${ }^{2}$ \\ ${ }^{1}$ Research and Development Centre, Bharathiyar University, Coimbatore, Tamilnadu, India \\ ${ }^{2}$ Biochemistry Faculty, Department of Chemistry and Biosciences, Sastra University, Srinivasa Ramanujan Centre, Kumbakonam, \\ Tamilnadu India
}

Email address:

revathy.reva@gmail.com (J. Revathy), sheikhaneef@yahoo.co.in (S. S. Abdullah)

${ }^{*}$ Corresponding author

To cite this article:

J. Revathy, S. Sheik Abdullah. The Role of Hesperetin in the Management of Diabetes Mellitus and Its Complications. Journal of Cancer Treatment and Research. Vol. 5, No. 1, 2017, pp. 1-6. doi: 10.11648/j.jctr.20170501.11

Received: October 31, 2016; Accepted: March 14, 2017; Published: March 17, 2017

\begin{abstract}
Diabetes mellitus is a chronic metabolic disease which is a serious global problem. Many antidiabetic therapies focus on improving insulin sensitivity, increasing insulin production, and/or decreasing the level of blood glucose. Hesperetin is a flavanoid commonly found in many herbal medicines and food. Hesperetin seem to demonstrate adequate properties. Animal studies were carried out for 45 days and at the end of $45^{\text {th }}$ day blood samples were collected and various biochemical parameters were measured using autoanalyser. They can inhibit enzymes involved in glucose metabolism, prevent the development of insulin resistance and normalize plasma glucose and insulin levels. This synthetic drug apart from producing a hypoglycemic effect has also been found to manifest hypolipidemic and anti-obesity activity. Hesperetin is also promising agents in the prevention of diabetic complications. They have strong antioxidant activity and inhibit the formation of advanced glycation end products, implicated in the pathogenesis of diabetic nephropathy, embryopathy, and neuropathy or impaired wound healing. Until now very few clinical studies have been concerned with the application of Hesperetin in treating diabetes. Our experimental findings with respect to the mechanism of action of synthetic compound in Streptozotocin induced diabetic rats suggest that it enhances insulin secretion by the islets of langerhans and enhances glucose utilization. However, due to their great therapeutic potential, these compounds deserve special attention.
\end{abstract}

Keywords: Hesperetin, Insulin, Hypoglycemic Effect, Hypolipidemic Activity

\section{Introduction}

Diabetes mellitus is a complex metabolic disorder characterized by chronic hyperglycemia with disturbances of carbohydrate, fat and protein metabolism that results from imperfections in insulin secretion, insulin action or both [1]. It is one of the most common metabolic disorders, and is considered to be one of the five leading causes of death worldwide $[2,3]$. The disease is multifactorial that has a significant impact in the health, quality of life and life expectancy of patients, as well as on the health care system [4]. The chronic hyperglycemia of diabetes is associated with long-term damage, dysfunction and failure of various organs, especially the eyes, kidneys, nerves, heart and blood vessels [5]. Impairment of growth and susceptibility to certain infections may also accompany with chronic hyperglycemia. Mortality and morbidity associated with diabetes is mainly due to complications arising from it which include neuropathy, nephropathy, vasculopathy and retinopathy $[6,7]$. Flavanoids are non-nutritive dietary components that are widely distributed in plants, several types of vegetables and fruits, and it has been suggested that flavanoids are associated with potential health benefits [8]. The flavanoid hesperetin is the aglycone of hesperidin found in sweet oranges, other citrus fruits and some herbs. Biological activities of hesperetin include antioxidant, bone-sparing and lipid lowering effects [9]. Hesperetin also plays a significant role in inflammation and cancer inhibition. Chemical 
compounds that selectively damage pancreatic p-cells constitute a class of diabetogenic agents. Among such compounds, alloxan and streptozotocin exhibit the most potent diabetogenicity, and have been widely used for induction of experimental diabetes [10]. The present study was undertaken to study the antidiabetic effect of hesperetin using In vivo analysis and to determine the biochemical parameters in normal and Streptozotocin induced diabetic rats.

\section{Materials and Methods}

\subsection{Animal Management}

Nine-week-old adult male albino rats of Wistar albino strain, weighing 120-150 g were acclimatized for one week at air conditioned room $\left(25 \pm 1{ }^{\circ} \mathrm{C}\right)$ and relative humidity $(55 \%)$ in a 12-hour light/dark cycle in a room under hygienic condition.

This study was carried out in the animal house of Srimad Andavan College, Tiruchirapalli and was approved by the Institutional Ethical Committee (SAC/IAEC/BC/2015/Ph.D009). Animals were fed with pelleted rat chow and water $a d$ libitum.

\subsection{Source of Chemicals}

The synthetic compound and all the chemicals and solvents were of analytical grade and purchased from SigmaAldrich Co and Himedia Laboratories Pvt.Ltd., Mumbai.

\subsection{Induction of Diabetes}

The rats were rendered diabetes by a single intraperitoneal injection of STZ $(45 \mathrm{mg} / \mathrm{kg}$ body weight) in a freshly prepared citrate buffer $(0.1 \mathrm{M}, \mathrm{PH} 4.5)$ after an overnight fast. STZ injected rats were given $20 \%$ glucose solution for $24 \mathrm{hr}$ to prevent initial drug-induced hypoglycemic mortality. After $72 \mathrm{hrs}$ of STZ injection rats exhibited massive glycosuria and hyperglycemia was confirmed by measuring the fasting blood glucose concentration. The rats with blood glucose levels more than $235 \mathrm{mg} / \mathrm{dL}$ were considered diabetic and used for the experiment.

\subsection{Treatment Group Protocol}

The animals were divided into six groups, each comprised of nine rats.

Group I - Normal Rats

Group II -Rats were induced with intraperitoneal injection of STZ ( $45 \mathrm{mg} / \mathrm{kg}$ body weight).

Group III - Rats were induced with intraperitoneal injection of STZ $(45 \mathrm{mg} / \mathrm{kg}$ body weight) and treated with Hesperetin ( $20 \mathrm{mg} / \mathrm{kg}$ body weight in saline).

Group IV - Rats were induced with intraperitoneal injection of STZ $(45 \mathrm{mg} / \mathrm{kg})$ and treated with Hesperetin (40mg/kg body weight in saline).

Group V - Rats were treated with Hesperetin $(40 \mathrm{mg} / \mathrm{kg}$ body weight in saline).
Group VI - Rats were induced with intraperitoneal injection of STZ $(45 \mathrm{mg} / \mathrm{kg})$ and treated with Glibenclamide ( $1 \mathrm{mg} / \mathrm{kg}$ body weight in saline).

\subsection{Collection of Blood Sample}

At the end of the experimental period, the rats were sacrificed. Plasma and serum were separated Treatment continued for 45 consecutive days. Before the treatment $\left(0^{\text {th }}\right.$, $3^{\text {rd, }} 15^{\text {th }}, 30^{\text {th }}$ day and the end 45 days plasma levels were estimated using the glucose oxidase method. At the end of the experimental period, the rats were sacrificed. Plasma and serum were separated from blood by centrifuging the samples at $5000 \mathrm{rpm}$ for $10 \mathrm{~min}$ and stored in a refrigerator until analysed.

\subsection{Biochemical Estimation}

All biochemical estimations were done by using fully automated analyzer (ERBA-EM 200). For serum glucose estimation glucose oxidase and peroxidase (GOD-POD) method, for triglycerides Glycerol Phosphate Oxidaseperoxidase (GPO-POD), for total cholesterol, HDL and LDL, Cholesterol Oxidase-Peroxidase (CHOD-PAP) methods were employed. VLDL was estimated using the formula, VLDL = triglycerides / 5 .

\subsection{Histopathology}

For histopathological study, rats from each group were perfused with cold physiological saline followed by formalin (10\% formaldehyde). Then dehydrated on treatment with a series of different concentration of ethanol and embedded in paraffin wax and thick sections are cut using microtome and stained with hematoxylin and eosin. The specimens are evaluated with light microscope.

\subsection{Statistical Analysis}

Results are presented as mean \pm S.D for six rats in each group. Data were analyzed by one-way analysis of variance (ANOVA) followed by Duncan's Multiple Range Test (DMRT) using SPSS version 10 (SPSS, Chicago, IL, USA). The limit of statistical significance was set at $p<0.05$.

\section{Results}

Table 1 showed the levels of plasma glucose, haemoglobin, insulin and glycosylated haemoglobin in normal control and experimental rats. The level of plasma glucose and glycosylated haemoglobin is significantly increased whereas plasma insulin and blood haemoglobin level was significantly decreased in diabetic control rats. Administration of hesperetin as well as glibenclamide brings a significant decrease in plasma glucose and increase in insulin level was observed at the end of the experimental period. Hesperetin at a dose of $40 \mathrm{mg} / \mathrm{kg}$ bw showed a highly significant effect than other dose $(20 \mathrm{mg} / \mathrm{kg} \mathrm{bw})$. 
Table 1. Effect of hesperetin on plasma glucose, haemoglobin, insulin and glycosylated haemoglobin levels in the control and experimental rats.

\begin{tabular}{lllll}
\hline Groups & Plasma glucose (mg/d) & Haemoglobin $(\mathbf{g} / \mathbf{d L})$ & Insulin $(\boldsymbol{\mu U} / \mathbf{m L})$ & HbA $\mathbf{C}(\mathbf{\%})$ \\
\hline Group I (control) & $89.00 \pm 1.20^{\mathrm{a}}$ & $15.20 \pm 0.12^{\mathrm{a}}$ & $16.12 \pm 0.08^{\mathrm{a}}$ & $4.64 \pm 0.02^{\mathrm{a}}$ \\
Group II (diabetic) & $215.67 \pm 1.41^{\mathrm{a}}$ & $9.86 \pm 0.19^{\mathrm{b}}$ & $7.23 \pm 1.01^{\mathrm{b}}$ & $8.38 \pm 0.02^{\mathrm{c}}$ \\
Group III (diabetic+20mg/kg bw hesperetin) & $150.17 \pm 1.69^{\mathrm{b}}$ & $11.47 \pm 0.06^{\mathrm{c}}$ & $11.13 \pm 1.01^{\mathrm{c}}$ & $6.91 \pm 0.02^{\mathrm{b}}$ \\
Group IV (diabetic+40mg/kg bw hesperetin) & $123.83 \pm 2.51^{\mathrm{c}}$ & $13.72 \pm 0.16^{\mathrm{d}}$ & $13.54 \pm 1.00^{\mathrm{d}}$ & $5.28 \pm 0.02^{\mathrm{a}}$ \\
Group V (control+40mg/kg bw hesperetin) & $94.00 \pm 5.98^{\mathrm{a}}$ & $14.61 \pm 0.10^{\mathrm{a}}$ & $17.21 \pm 0.08^{\mathrm{a}}$ & $5.00 \pm 0.02^{\mathrm{b}}$ \\
Group VI (diabetic +glibenclamide 1mg/kg bw) & $110.92 \pm 1.45^{\mathrm{d}}$ & $14.53 \pm 0.07^{\mathrm{d}}$ & $15.10 \pm 0.10^{\mathrm{d}}$ & $5.12 \pm 0.01^{\mathrm{a}}$ \\
\hline
\end{tabular}

Values are given as means \pm S.D from six rats in each group. Values In each column, different superscript letters mean significant differences at $p<0.05$ (DMRT)

Table 2. Effect of hesperetin on plasma glycoproteins levels in the control and experimental rats.

\begin{tabular}{lllll}
\hline Groups & Hexose (mg/dl) & Hexosamine (mg/dl) & Sialic acid (mg/dl) & Fucose (mg/dl) \\
\hline Group I (control) & $14.69 \pm 0.06^{\mathrm{a}}$ & $4.91 \pm 0.01^{\mathrm{a}}$ & $2.87 \pm 0.03^{\mathrm{a}}$ & $3.08 \pm 0.04^{\mathrm{a}}$ \\
Group II (diabetic) & $28.25 \pm 0.12^{\mathrm{b}}$ & $12.78 \pm 0.06^{\mathrm{b}}$ & $10.60 \pm 0.10^{\mathrm{b}}$ & $8.04 \pm 0.06^{\mathrm{b}}$ \\
Group III (diabetic+20mg/kg bw hesperetin) & $19.22 \pm 0.03^{\mathrm{a}}$ & $10.44 \pm 0.19^{\mathrm{a}}$ & $6.40 \pm 0.08^{\mathrm{a}}$ & $6.86 \pm 0.03^{\mathrm{a}}$ \\
Group IV (diabetic+40mg/kg bw hesperetin) & $16.12 \pm 0.14^{\mathrm{a}}$ & $6.98 \pm 0.05^{\mathrm{a}}$ & $3.97 \pm 0.03^{\mathrm{a}}$ & $4.06 \pm 0.06^{\mathrm{a}}$ \\
Group V (control+40mg/kg bw hesperetin) & $15.21 \pm 0.11^{\mathrm{a}}$ & $6.05 \pm 0.07^{\mathrm{a}}$ & $3.83 \pm 0.04^{\mathrm{a}}$ & $3.06 \pm 0.02^{\mathrm{a}}$ \\
Group VI (diabetic +glibenclamide 1mg/kg bw) & $15.65 \pm 0.07^{\mathrm{a}}$ & $5.79 \pm 0.06^{\mathrm{a}}$ & $3.60 \pm 0.05^{\mathrm{a}}$ & $3.60 \pm 0.08^{\mathrm{a}}$ \\
\hline
\end{tabular}

Values are given as means \pm S.D from six rats in each group. Values In each column, different superscript letters mean significant differences at $p<0.05$ (DMRT).

Table 2 shows the changes in the levels protein bound hexose, hexosamine, fucose and sialic acid in plasma of control and experimental rats. Significantly higher levels of glycoprotein components were observed in the plasma of diabetic rats when compared to normal rats. Oral administration of hesperetin as well as glibenclamide to diabetic rats resulted in a significant reduction of protein bound hexose, hexosamine, fucose and sialic acid in plasma when compared to diabetic control rats.

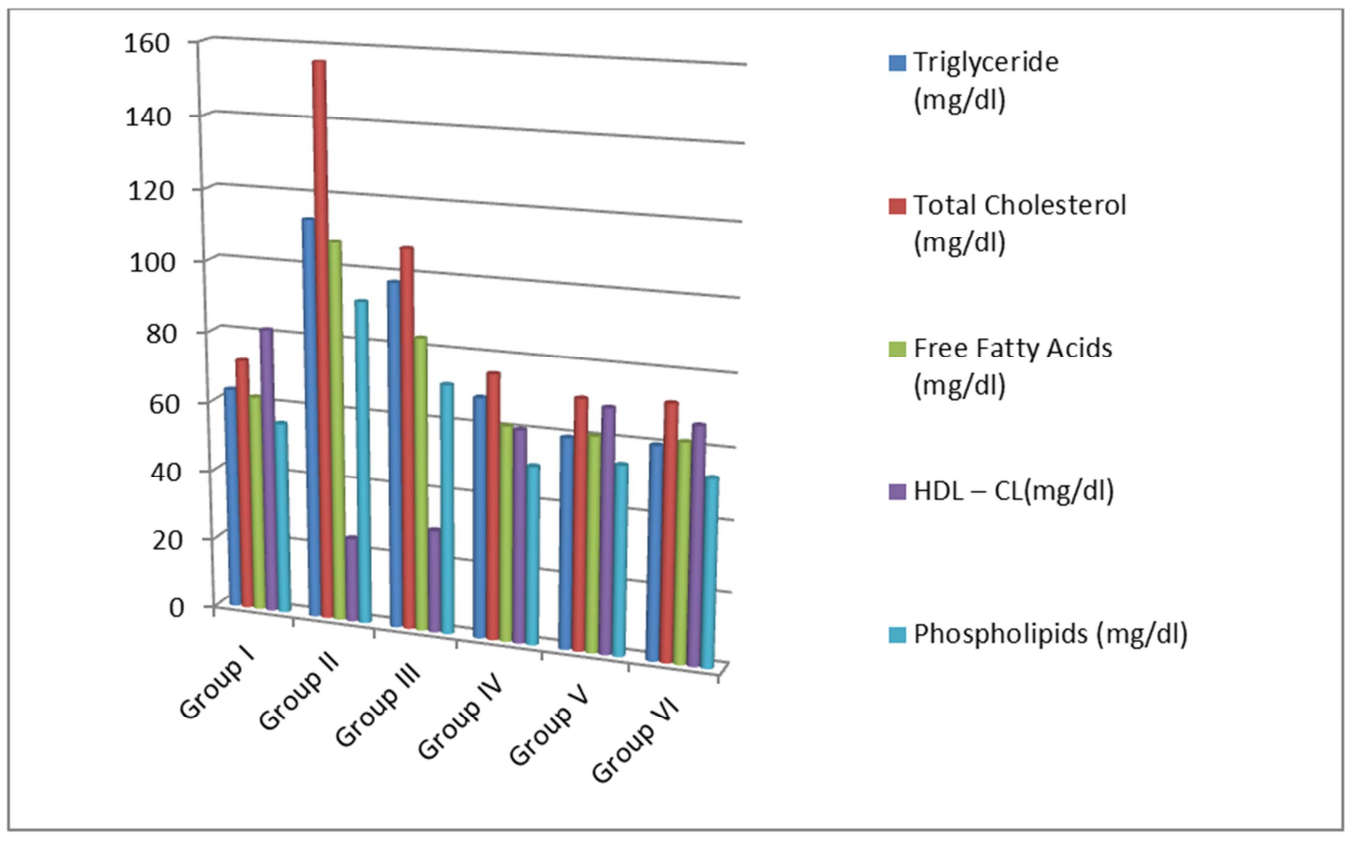

Figure 1. Effect of hesperetin on lipid profiles in the control and experimental rats.

Figure 1 depicts the levels of triglycerides, total cholesterol, free fatty acids and phospholipids were significantly $(p<0.05)$ increased, whereas the levels of HDL-Cholesterol (HDL-C) was significantly $(\mathrm{p}<0.05)$ decreased in STZ induced diabetic rats (group II) compared to control rats. Oral supplementation with hesperetin (40mg/kg body weight) shows the pronounced effect.

Figure 2 A-E represents the photomicrographs of hematoxylin-eosin staining of pancreatic tissues of control and experimental rats. Fig. 2A shows the section of pancreatic tissues of control and experimental rats. Fig. 2 A shows the section of pancreatic tissue of control rats shows normal pancreas with both exocrine and endocrine including islets. Fig. B shows the pancreas of diabetic rats exhibiting mild degenerative changes of islets. Fig. D shows normal group treated with hesperetin $(40 \mathrm{mg} / \mathrm{kg}$ bw). Fig. C and E shows more pronounced in the rats supplemented with hesperetin $(40 \mathrm{mg} / \mathrm{kg}$ bw) and the reference drug glibenclamide $(1 \mathrm{mg} / \mathrm{kg} \mathrm{bw})$. 

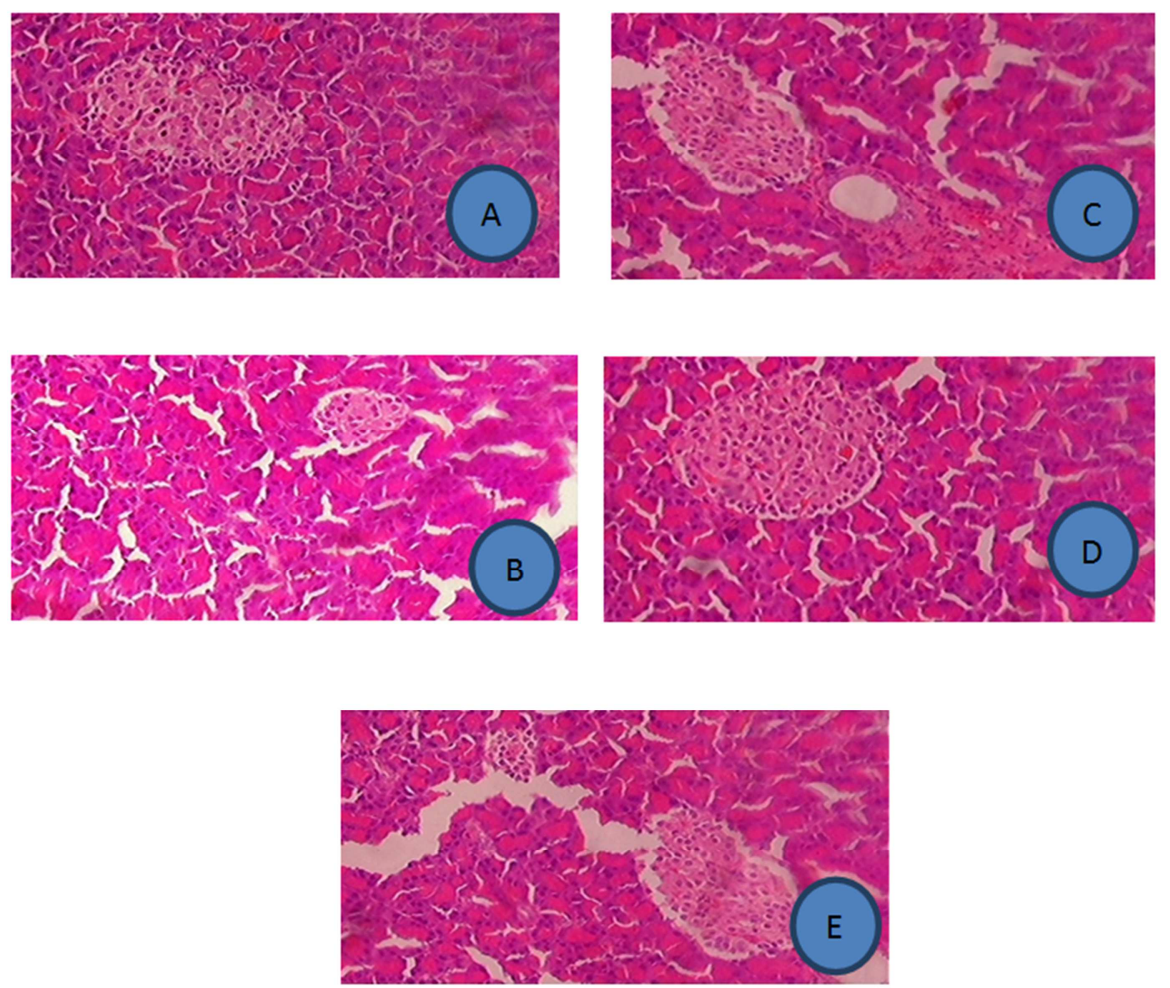

Figure 2. Photomicrographs of hematoxylin-eosin staining of pancreatic tissues of control and experimental rats.

Histological photograph of (A) control, (B) diabetic control, (C) diabetic+ hesperetin (40mg/kg bw), (D) control+ hesperetin (40mg/kg bw), (E) glibenclamide $(1 \mathrm{mg} / \mathrm{kg} \mathrm{bw})$.

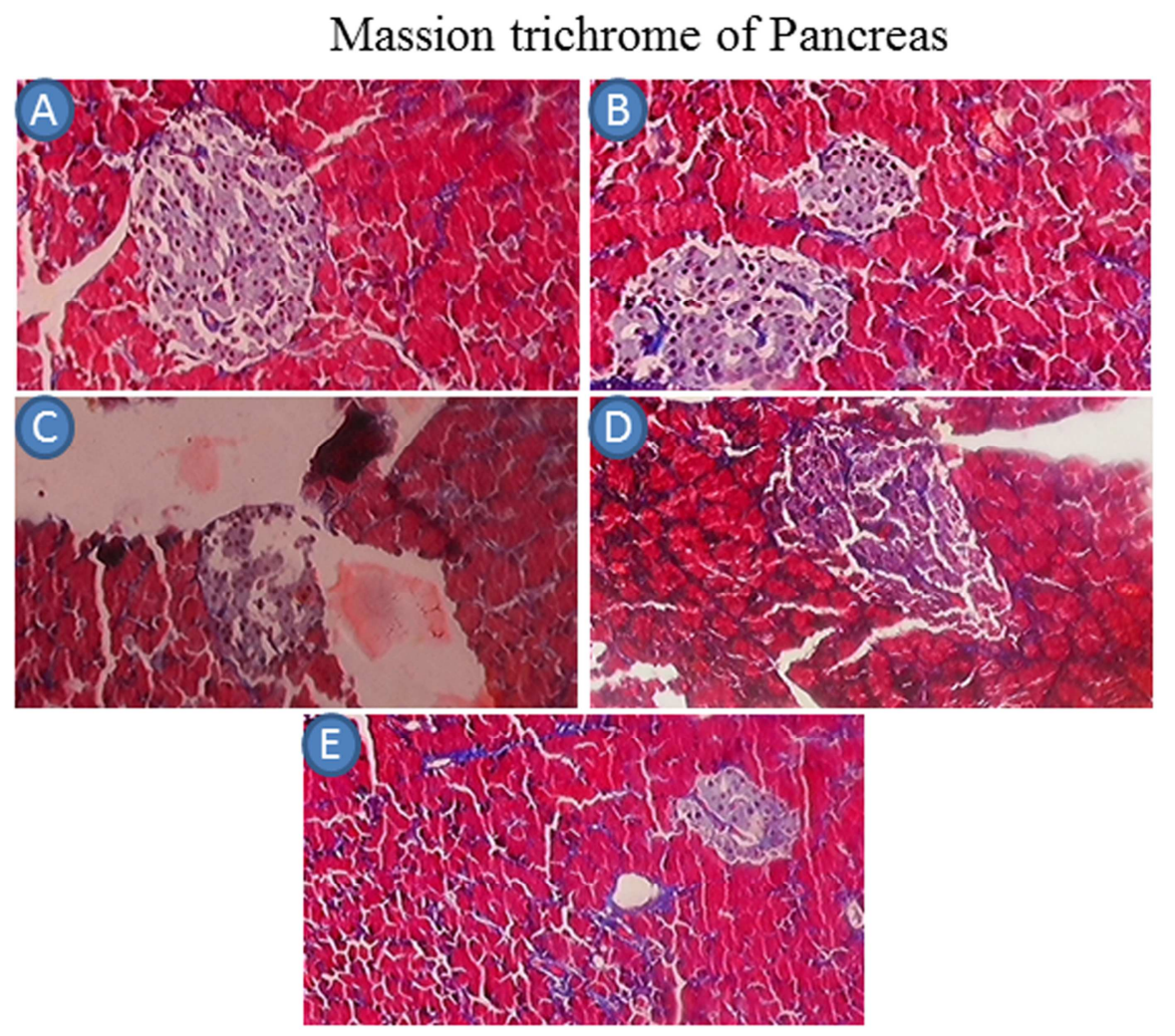

Figure 3. Photomicrographs of Massion trichrome staining of pancreatic tissues of control and experimental rats.

Histological photograph of (A) control, (B) diabetic control, (C) diabetic+ hesperetin (40mg/kg bw), (D) control+ hesperetin (40mg/kg bw), (E) glibenclamide $(1 \mathrm{mg} / \mathrm{kg} \mathrm{bw})$. 
Figure 3 A-E represents the photomicrographs of hematoxylin-eosin staining of pancreatic tissues of control and experimental rats. Fig. 3A shows the section of pancreatic tissues of control and experimental rats. Fig. $3 \mathrm{~A}$ shows the section of pancreatic tissue of control rats shows normal pancreas with both exocrine and endocrine including islets. Fig. B shows the pancreas of diabetic rats exhibiting mild degenerative changes of islets. Fig. D shows normal group treated with hesperetin $(40 \mathrm{mg} / \mathrm{kg}$ bw). Fig. C and $\mathrm{E}$ shows more pronounced in the rats supplemented with hesperetin $(40 \mathrm{mg} / \mathrm{kg} \quad \mathrm{bw})$ and the reference drug glibenclamide $(1 \mathrm{mg} / \mathrm{kg}$ bw).

\section{Discussion}

In the present research, we found that oral administration of hesperetin for 45 days resulted in a significant reduction in plasma glucose concentrations and an increase in insulin levels in diabetic rats. The antidiabetic effect of hesperetin may be due to the increased release of insulin from the existing $\beta$-cells and/or regenerated $\beta$-cells of pancreas, restored insulin sensitivity or inhibition of intestinal absorption of glucose or enhanced the utilization of glucose by peripheral tissues. These results are in agreement with Ramachandran and Saravanan [11]. Hexoses of which glucose is one example evolved as energy sources critical for life. The elevated level of hexoses in diabetic rats may be associated with disturbances with carbohydrate metabolism. Treatment with hesperetin and glibenclamide in diabetic rats showed significant reduction in hexoses due to improved glycemic control. The level of hexosamine, increased significantly in the plasma and tissues of diabetic rats which may be due to insulin deficiency, this leads to depressed utilization of glucose by insulin-dependent pathway, thereby enhancing the formation of hexose and hexosamine [12].

Fucose is a member of the group of eight essential sugars the body requires for optimal function of cell-to-cell communication and its metabolism appears to be altered in various diseases such as diabetes mellitus [13]. Our results are finding in line with the study of reduced fucose by improved secretion of insulin in coumarin treated diabetic rats [14]. Sialic acid is the terminal residue of the oligosaccharide side chain of glycoproteins and widely occurs in the exposed positions of molecules like hormones, enzymes and also on tissues [15]. Various factors cause elevation in the concentration of plasma sialic acid. Among various factors first increase in synthesis of sialic acid in insulin-independent tissues, such as the liver and the brain, and the second is an increase in the activity of sialytransferase, which transfers the sialic acid residues to the glycolipids and glycoproteins [16]. Previous studies show that diosmin, produce the same effect in experimental diabetic rats [17].

Insulin has a potent inhibitory effect on lipolysis in adipocytes. Insulin deficiency leads to excess lipolysis and increased influx of free fatty acids to the liver $[18,19]$. In the present study we have observed higher levels of cholesterol, triglycerides due to increased mobilization of free fatty acid from peripheral deposits, as insulin inhibits the hormonesensitive lipase. Pancreas of diabetic rats showed shrinkage of islets with mild degenerative changes and treatment with hesperetin showed normal islets with reduced fatty changes (H\&E).

\section{References}

[1] American Diabetes Association. Diagnosis and classification of diabetes mellitus. Diabetes care. 2011; 34 (1) 62-68.

[2] Kim JJ, Ramesh T, Kim JS. Protective effects of chrysanthemum Flower extract against streptozotocin-induced oxidative damage in diabetes mice. Journal of medicinal plant research. 2012; 6 (4): 22-630.

[3] Huizinga MM, Rothman RL. Addressing diabetes pandemic. A comprehensive approach Indian J. Med. Res. 2006; 124: 481-484.

[4] Eze ED, Mohammed A, Musa KY, Tanko Y, Isa AS. Effect of ethanolic leaf extract of mucunapruriens (fabaceae) on lipid profile in alloxan-induced diabetes wister rats. British $J$ pharm Toxicol. 2012; 3 (3): 102-109.

[5] WHO use of glycated Haemoglobin (HbAlc) in the diagnosis of diabetes mellitus. Abbreviated report of a WHO consultation. 2011; 1-25.

[6] Ahmed MF. Kazim SM, Ghori SS, Mehjabeen SS, Ahmed SE, Ali SM. Ibrahim M. Antidiabetes activity of vincabosea extracts in alloxan- induced diabetes rats. International journal of endocrinology. Article ID 841090, 2010: 1-6.

[7] Laakso M. Heart in diabetes: A microvascular disease Diabetes care. 2011; 34 (2): 145-149.

[8] Cao H, Hininger-Favier I, Kelly M. A, Benaraba R, Dawson H. D, Coves S, Roussel A. M, and Anderson R. A, J. Agric. Food C., 55, 6372-6378 (2007).

[9] Horcajada, M. N., Habauzit, V., Trzeciakiewicz, A., Morand, C., Gil-Izquierdo, A., Mardon, J., Lebecque, P., Davicco, M. J., Chee, W. S. S., Coxam, V., Offord, E., J. Appl. Physiol. $2008,104,648$.

[10] Szkudelski. The Mechanism of Alloxan and Streptozotocin Action in B Cells of the Rat Pancreas. Physiol. Res. 2001; 50: 536-546.

[11] Ramachandran V, Saravanan R. Efficacy of asiatic acid, a pentacyclic triterpene on attenuating the key enzymes activities of carbohydrate metabolism in streptozotocininduced diabetic rats. Phytomedicine 2013; 20: 230-236.

[12] Rajamani U, Joseph D, Roux S, Essop MF. The hexosamine biosynthetic pathway can mediate myocardial apoptosis in a rat model of diet-induced insulin resistance. Acta Physiol 2011; 202: $151-157$

[13] Gomathi D, Ravikumar G, Kalaiselvi M, Devaki K, Uma C, Protective effect of the whole plant extract of Evolvulus alsinoides on glycoprotein alterations in streptozotocin induced diabetic rats. J Acu Dis 2013; 2: 148-150. 
[14] Pari L, Rajeswari N. Protective role of coumarin on plasma and tissue glycoprotein components in streptozotocinnicotinamide induced hyperglycemic rats. Int J Biol Med Res 2010; $1: 61-65$.

[15] Ciftci G, Cenesiz S, Yarim GF, Nisbet O, Nisbet C, Cenesiz M, Guvene D. Effect of fluoride exposure on serum glycoprotein pattern and sialic acid level in rabbits. Biol Trace Elem Res 2010; 133: 51-59.

[16] Romero AC, Ibuki FK, Nogueira FN. Sialic acid reduction in the saliva of streptozotocin induced diabetic rats. Arch Oral Biol 2012; 57: 1189-1193.
[17] Pari L, Srinivasan S. Preventive effect of diosmin, a bioflavonoid, on glycoprotein changes in streptozotocinnicotinamide-induced type 2 diabetic rats. In J Pharm Sci Res 2010; 10: 89-95.

[18] Coppack, S. W., Jenson, M. D., Miles, J. M. 1994. Invivo regulation of lipolysis in human. J. Lipid Res., 35: 177-193.

[19] Ohno, T., Horio, F., Tanaka, S., Terada, M., Namikawa, T. and Kitoh, J. 2000. Fatty liver and hyperlipidemia in IDDM of streptozotocin treated shrews. Life Sci., 66: 125-131. 